\title{
An N-terminal WT1 mutation (P181S) in an XY patient with ambiguous genitalia, normal testosterone production, absence of kidney disease and associated heart defect: enlarging the phenotypic spectrum of WT1 defects
}

\author{
Birgit Köhler ${ }^{1}$, Catherine Pienkowski ${ }^{2}$, Françoise Audran ${ }^{1}$, Martine Delsol $^{3}$, Maite Tauber ${ }^{2}$, Françoise Paris ${ }^{1,4}$, \\ Charles Sultan ${ }^{1,4}$ and Serge Lumbroso ${ }^{1}$ \\ ${ }^{1}$ Service d'Hormonologie and Institut National de la Santé et de la Recherche Médicale U540, CHU Montpellier, ${ }^{2}$ Service d'Endocrinologie Pédiatrique, \\ ${ }^{3}$ Service d'Anatomie Pathologique, CHU Toulouse and ${ }^{4}$ Unité d'Endocrinologie Pédiatrique, CHU Montpellier, France \\ (Correspondence should be addressed to S Lumbroso; Email: lumbroso@montp.inserm.fr)
}

\begin{abstract}
Objective: This study reports the clinical and molecular data of an XY patient with a very unusual phenotype due to a Wilms' tumor-suppressor (WT1) gene mutation. The genotype-phenotype relationship of different WT1 mutations is then discussed.

Patient: The patient presented at birth with micropenis, severe hypospadias and cryptorchidism. Normal androgen production and an absence of clinical response to a testosterone treatment trial suggested partial androgen resistance. Eventually, female sex of rearing was chosen. At the beginning of puberty, normal male androgen production occurred, and subsequent gonadectomy did not show gonadal dysgenesis. It is notable that the patient, now 20 years of age, has not developed kidney disease. In addition to the genital malformation, the patient displayed an associated congenital heart defect, consisting of a coarctation of the aorta and a patent ductus arteriosis (PDA).

Results: No mutations were detected in the androgen receptor or $5 \alpha$-reductase genes. Direct sequencing of the WT1 gene identified a heterozygous proline to serine substitution at position 181 (P181S). The same heterozygous mutation was found in the mother. Interestingly, the mother shows no signs of kidney disease at her present age of 49 .

Conclusion: This is the first germline missense mutation in the N-terminal part of WT1 identified in a patient with the very particular phenotype of ambiguous genitalia with absence of gonadal dysgenesis and kidney disease. The possible molecular mechanisms leading to the patient's phenotype are considered. The high frequency of PDA in newborns and the absence of heart abnormalities in XX females carrying the P181S mutation, however, suggest that the heart defect was most likely a coincidental association. This case enlarges the clinical spectrum of WT1 defects and may provide new insights into the complex functions of WT1 in genital and kidney development.
\end{abstract}

European Journal of Endocrinology 150 825-830

\section{Introduction}

The Wilms' tumor-suppressor (WT1) gene encodes a transcription factor of the zinc finger family which is known to play a major role in the development of the kidney and gonad. The gene was cloned in 1990 through patients with WAGR syndrome (Wilms' tumor, aniridia, genitourinary malformation and mental retardation) who presented deletions of chromosome 11p13 (1). The WT1 gene consists of 10 exons and spans $50 \mathrm{~kb}$. It may encode 24 protein isoforms through a combination of alternative splicing, alternative translational start sites and RNA editing. All these proteins share four C-terminal zinc fingers which are necessary for DNA/RNA-binding. The N-terminal part of WT1 is also of special functional importance, as it contains the self-association, repression and activation domains of the protein, as well as an RNA recognition motif (2). The two major isoforms are produced through alternative splicing at the end of exon 9, resulting in an insertion $(+\mathrm{KTS})$ or exclusion ( $-\mathrm{KTS})$ of lysine, threonine and serine residues between zinc fingers 3 and 4 . The + KTS and - KTS isoforms may perform distinct functions, as they are conserved during evolution. The + KTS isoform mainly plays a role in RNA processing and the - KTS isoform in transcriptional activity (3). Several lines of evidence have shown that WT1 can act as either a transcriptional activator or a repressor, both in vitro and in vivo $(2,4)$.

Since the cloning of WT1 in WAGR syndrome, numerous WT1 mutations have been described in two other syndromes associated with kidney disease 
and genital malformation. In the complete DenysDrash syndrome (DDS), WT1 missense mutations in the zinc finger-coding region cause genital malformations in XY individuals, early-onset renal failure due to diffuse mesangial sclerosis and Wilms' tumor (5). In Frasier syndrome, intron 9 splice-site mutations affecting the balance of the + KTS/-KTS isoforms were found to result in partial to complete male to female sex reversal, late-onset renal failure due to focal glomerulosclerosis, and gonadoblastoma (6). In addition to these two-well defined disorders, WT1 nonsense mutations were found in several patients with genital abnormalities with or without Wilms' tumor $(7,8)$ and nephropathy $(7,9,10)$. These observations suggested that mutations of the WT1 gene are not the cause of a defined syndrome, but rather lead to a broad spectrum of disorders of the kidney and male sex differentiation (11).

In this report we present the first N-terminal WT1 missense mutation (P181S) identified in an XY adult patient with a very unusual phenotype: ambiguous genitalia but normal testosterone production, absence of kidney disease and an associated congenital heart defect.

\section{Case report}

\section{Clinical presentation}

The patient was born with ambiguous genitalia and congenital heart disease. During pregnancy, the mother did not receive any medication. Birth weight was $2480 \mathrm{~g}$ and birth length was $46 \mathrm{~cm}$ at 37 weeks of gestation. The genital malformation consisted of a $2.5 \mathrm{~cm}$ clitoris-like phallus, no palpable gonads, fusion of the labioscrotal folds, and a single perineal opening representing a urogenital sinus. The karyotype was 46 ,XY. Genitography showed a vaginal cavity of $2 \mathrm{~cm}$ in length. Laparotomy revealed no uterus and gonads located in the ovarian position in the pelvis. On the right side, no vas deferens was seen, and the epididymis was not attached to the gonad. On the left side, the epididymis and vas deferens were found in a normal position. Gonadal biopsy showed normal bilateral testes (Fig. 1 ). Sonography did not show kidney abnormalities. The cardiac malformation consisted of a coarctation of the aorta and a patent ductus arteriosus.

\section{Hormonal studies}

At birth, a testosterone (T) level of $0.31 \mathrm{ng} / \mathrm{ml}$ was found. Basal luteinizing hormone ( $\mathrm{LH})$, follicle-stimulating hormone (FSH) and 17 hydroxyprogesterone after adrenocorticotropic hormone (ACTH) stimulation were normal. Human chorionic gonadotropin (HCG) stimulation $(3 \times 1500 \mathrm{IU})$ led to a normal testosterone rise from 0.4 to $4.92 \mathrm{ng} / \mathrm{ml}$ (Table 1 ). A testosterone treatment trial did not show growth of the penoclitoridal structure. Consequently, the diagnosis of partial androgen resistance was suggested.

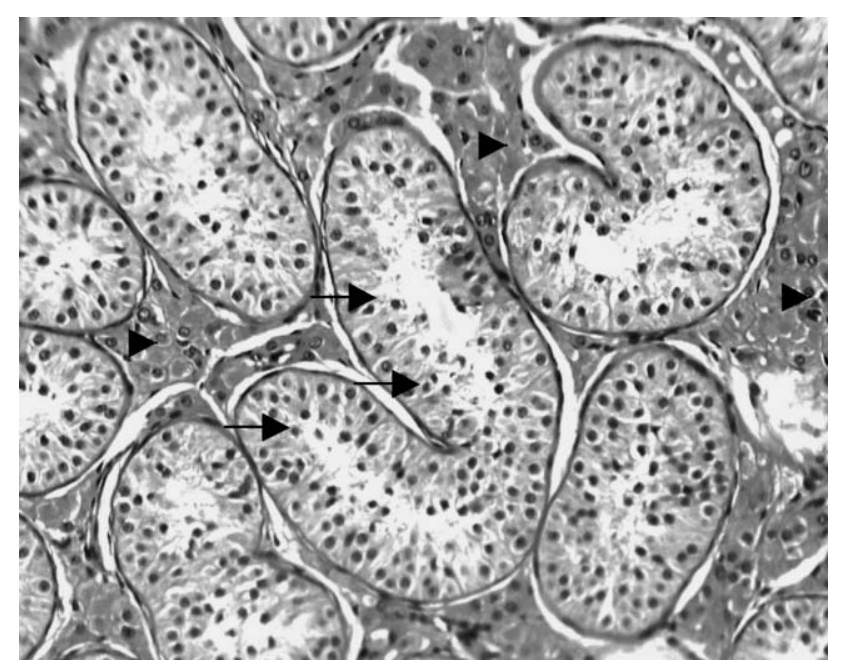

Figure 1 Gonadal histology of the patient's testes at the age of 11 (hematoxylin and eosin $\times 10$ magnification) showing eutrophic testes with seminiferous tubules of normal size, increased number of Sertoli cells (arrow) and Leydig cell hyperplasia (arrowhead).

Table 1 Hormonal data of the patient at birth and at 11 years.

\begin{tabular}{llccc}
\hline & At birth & Normal values (males) & At 11 years & Normal values (males) \\
\hline Testosterone (ng/ml) & & & & \\
$\quad$ Basal & 0.4 & $(0.01 \pm 0.56)$ & 2.22 & $(0.5 \pm 0.28)$ \\
$\quad$ After HCG stimulation & 4.92 & $(7.26 \pm 2.43)$ & n.d. & $(0.089 \pm 0.043)$ \\
DHT (ng/ml) & n.d. & & 0.17 & $(4.3 \pm 4.8)$ \\
LH (U/l) & 5 & $(6 \pm 3.7)$ & 5.2 & $(16.2 \pm 12.5)$ \\
$\quad$ Basal & n.d. & & 44 & $(3.2 \pm 2.3)$ \\
After stimulation & 4.5 & $(1.5 \pm 0.8)$ & 18 & $(8.6 \pm 5.4)$ \\
FSH (U/l) & n.d. & & 18 & $(15-29.6)$ \\
$\quad$ Basal & n.d. & & 4.3 & \\
After LHRH stimulation & & & & \\
AMH (ng/ml) & & & & \\
\end{tabular}

$\mathrm{DHT}$, dihydrotestosterone; LH, luteinizing-hormone; $\mathrm{FSH}$, follicle-stimulating hormone; LHRH, LH releasing hormone; $\mathrm{AMH}$, antimüllerian hormone. 


\section{Sex assignment}

Female sex assignment was chosen according to the clinical phenotype and the partial androgen resistance. At 1 year of age, a feminizing genitoplasty with opening of the urogenital sinus and burying of the penoclitoridal structure was performed. The gonads were not removed.

\section{Follow-up during childhood}

The patient is now a 20-year-old woman. The coarctation of the aorta and the patent ductus arteriosus were operated on at the age of 8 . At 10 years of age, growth of pubic hair without breast development occurred. Hormonal evaluation at the age of 11 revealed a testosterone level of $2.22 \mathrm{ng} / \mathrm{ml}$. Dihydrotestosterone (DHT) level was $0.17 \mathrm{ng} / \mathrm{ml}$ with a normal T/DHT ratio of 13 . LHRH testing showed an exaggerated response of $\mathrm{LH}$ from 5.2 to $44 \mathrm{U} / \mathrm{l}$ and a slightly elevated FSH of $18 \mathrm{U} / \mathrm{l}$. Antimüllerian hormone (AMH) of $4.3 \mathrm{ng} / \mathrm{ml}$ was below the normal range for Tanner stage II (Table 1). No growth of the clitoris under the influence of elevated androgen levels at the beginning of puberty was observed. Subsequently, gonadectomy was performed. Both gonads were of normal size for age. Histology revealed 'Sertoli-rich' seminiferous tubules with rarification of spermatogonia and Leydig cell hyperplasia (Fig. 1). There were no signs of gonadoblastoma. Until now, follow-up of renal function has not revealed proteinuria.

\section{Molecular analysis}

\section{Methods}

Genomic DNA was extracted from peripheral blood leukocytes with the Qiamp DNA blood kit (Qiagen, Courtaboeuf, France). Exons 1-8 of the androgen receptor gene and exons $1-5$ of the $5 \alpha$-reductase type 2 gene were amplified by polymerase chain reaction (PCR). Sets of primers and reaction conditions were used as described previously $(12,13)$. Exons $1-10$ of the WT1 gene were amplified using the following primers:

Ex1F 5'-CAGCGCTGAACGTCTCCA-3', Ex1R 5'-GGGTGTCCTAGAGCGGAGAG-3', Ex2F 5'-GTGGCTGGTTCAGACCCAC-3', Ex2R 5'-AATTCCTGGGGAGAGGAG-3', Ex3F 5'-TCTCGTGTCTCCCCCAAC-3', Ex3R 5'-GGT-CCCAAGGACCCAGAC-3', Ex4F 5'-TCCATTGCTTTTGAAGAAACAG-3', Ex4R 5'-CTTTGAAATGGTTCAAACAGG-3', Ex5F 5'-CACTGGATTCTGGGATCTGG-3', Ex5R 5'-GCC AGTCAGCAAGGCCTAC-3', Ex6F 5'-ATTT-CCAAATGGCGACTGTG-3', Ex6R 5'-AAAGGGCCGGTAAGTAGG AA-3', Ex7F 5'-CTCCAGTGCTCACTCTCCCT-3', Ex7R 5'-CTCTTGAACCATGTTTGCCC-3', Ex8F 5'-CCTAGTAGGAGAGGTTGCCTTT-3', Ex8R 5'-TCAT-GAAATCAACCCTAGCCC-3', Ex9F 5'-GAAGTCAGCCTTGTGGGC-3', Ex9R 5'-CTCATCACAATTTCATTCCACA-3', Ex10F 5'-CTTCACTCGGGCCTTGATAG-3', Ex10R 5'-TGAGGAGGAGTGGAGAGTCAG-3'.
PCRs were performed with the Taq PCR Master Mix Kit (Qiagen). PCR products were verified for correct length on agarose gel and purified, using Qiaquick PCR columns (Qiagen). Automatic sequencing of the PCR products was performed with the ABI Prism BigDye terminator sequencing kit and the ABI 310 genetic analyzer according to the manufacturer's instructions (Applied Biosystems, Courtaboeuf, France).

\section{Results}

Molecular analysis of the androgen receptor was performed in early childhood, as the phenotype and the hormonal data pointed to partial androgen insensitivity syndrome. No sequence abnormality was found. As Wolffian ducts were present, in later childhood molecular analysis of the $5 \alpha$-reductase type 2 gene was performed, and no sequence abnormalities were detected. Subsequently, after ruling out these most common genetic defects leading to disturbed sex differentiation, sequencing of the WT1 gene was performed. A heterozygous $\mathrm{C}$ to $\mathrm{T}$ mutation was found in exon 2 , changing proline to serine at position 181 (Fig. 2). The same heterozygous mutation was detected in the genomic DNA of the healthy mother. The father did not carry the mutation (data not shown).

\section{Discussion}

The patient's mutation (P181S) is the first germline WT1 missense mutation in the N-terminal coding region identified in an XY individual with genital malformation, normal androgen-producing testes and absence of kidney disease (Fig. 2). In addition, the patient presented an associated congenital heart defect. The patient inherited the mutation from the heterozygous XX mother, who has developed neither nephropathy nor Wilms' tumor at her present age of 49 .

The same P181S mutation was previously described in two patients. The mutation was identified in the tumoral tissue of an XY patient with Wilms' tumor, but without genital malformation (14), and Schumacher et al. reported a germline P181S substitution in an XX female with Wilms' tumor (15).

In comparison to the vast majority of WT1 mutations in the C-terminal DNA-binding zinc finger region, very few $\mathrm{N}$-terminal germline mutations have been reported. Through the WT1 mutation database (http://www.umd.necker.fr:2003/), it was suggested that N-terminal nonsense mutations, in contrast to Cterminal mutations, do not result in nephropathy but only in Wilms' tumor (8) (Fig. 2).

C-terminal and N-terminal WT1 mutations act through different mechanisms. The C-terminal WT1 mutants exert a dominant negative effect, as in DDS, since they lose their DNA-binding and transactivation capacities but retain their self-association domain, 


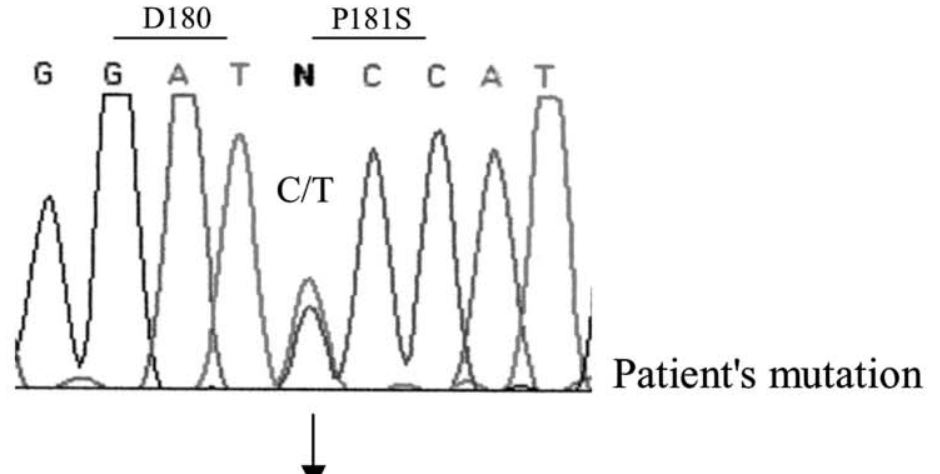

WT1 functional domains

self-association domain

zinc finger region

DNA/RNA binding

\section{exons}

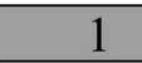

1

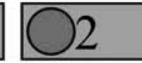

3

P181S

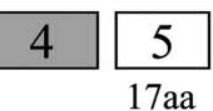

17 aa

6

7

7

8

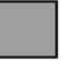

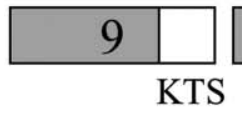

10

\section{Early-onset Nephropathy}

\section{Late-onset Nephropathy}

No Nephropathy

missense and nonsense mutations

Figure 2 The patient's mutation represented as the partial sequence of exon 2 of the WT1 gene, showing a heterozygous C to T mutation leading to a proline to serine substitution at position 181 (P181S). The different types and 'hot spots' of WT1 mutations in patients with early-onset, late-onset and absence of clinical nephropathy are indicated. 
which is essential for dimerization (16). In Frasier syndrome, the imbalance of + KTS and - KTS caused by intron 9 splice-site mutations might alter the expression of downstream genes necessary for normal development and function of the kidneys and gonads (6).

The P181S mutation in the early N-terminal part of the protein is not likely to hamper the DNA-binding and RNA-processing properties. But it can be assumed that the P181S mutation alters the self-associating capacities of WT1, as the mutation is located in the self-associating domain. In vitro studies are warranted to address this question. However, these studies of WT1 are extremely difficult and not very reliable, since WT1 function can change from repression to activation and vice versa depending on cell lines, expression vectors and the promoter of target genes $(2,4)$.

The absence of Wilms' tumor in our patient, in contrast to the other described patients with the P181S mutation, is probably due to the absence of a 'second hit' on the intact allele, which is necessary for tumor development (17).

To our knowledge, only two patients with WT1 mutations, XY karyotype and normal androgen-secreting gonads during puberty have been described (10, 18). The two patients presented severe hypospadias and cryptorchidism at birth. They showed normal masculinization during puberty with normal androgen levels, but elevated FSH and LH. At birth, our patient also displayed severe hypospadias and micropenis. Leydig cell function was intact with normal testosterone levels before and after HCG stimulation. At 11 years of age, testes were of normal size with 'Sertolirich' seminiferous tubules, absence of spermatogonia and Leydig cell hyperplasia with normal testosterone production (Fig. 1). The low AMH level at this age is difficult to explain. It indicates disturbed Sertoli cell function, but our patient had no müllerian remnants. One might therefore suspect a progressive alteration in Sertoli cell function with age.

The apparent phenotype of undervirilization with normal testosterone production in the neonatal and pubertal periods led to the diagnosis of androgen resistance. Since the androgen receptor gene sequence was normal, one could hypothesize that WT1 has some regulatory impact on androgen receptor function or expression. The androgen receptor promoter contains multiple WT1 binding sites (19), and it has been shown in vitro that WT1 could regulate androgen receptor transcription (19). Unfortunately, no genital skin fibroblasts of the patient were available to study androgen receptor expression.

Genotype-phenotype analysis of the reported cases suggests that the type of WT1 mutation might influence the severity of the gonadal malformation, as it does in the development of nephropathy (Fig. 2). Missense and splice-site mutations, which lead to an alteration in the zinc finger-coding region and the subsequent DNA- and RNA-binding functions, most likely result in a more severe phenotype, ranging from gonadal dysgenesis to streak gonads with a high risk of gonadoblastoma. In patients with N-terminal mutations, gonadal histology might reveal a less severe clinical spectrum from normal testis to mild gonadal dysgenesis. Androgen secretion might remain mainly intact in later life $(7,8)$.

Regarding the heart defect presented by our patient, the mice knockout phenotype (20) and in vitro data suggest a role of WT1 in heart development (21-23). However, the XX mother and the reported XX female carrying the P181S mutation did not display a heart defect, and coarctation of the aorta and patent ductus arteriosus are frequent abnormalities. The patient's heart defect is thus most likely a coincidential association.

The particular phenotype of our patient, with genital malformation, normal androgen-producing testes and absence of nephropathy in both patient and mother, gives further evidence that N-terminal nonsense and missense mutations do not lead to nephropathy. However, they can lead to genital malformation, suggesting that genital development is more sensitive to gene dosage than kidney development in humans (24).

\section{Acknowledgement}

This work was supported by the ESPE Research Fellowship sponsored by Novo Nordisk AIS (to BK).

\section{References}

1 Call KM, Glaser T, Ito CY, Buckler AJ, Pelletier J, Haber DA et al. Isolation and characterization of a zinc finger polypeptide gene at the human chromosome 11 Wilms' tumor locus. Cell 1990 $60509-520$.

2 Scharnhorst V, van der Eb AJ \& Jochemsen AG. WT1 proteins: functions in growth and differentiation. Gene $2001 \mathbf{2 7 3}$ 141-161.

3 Hastie ND. Life, sex, and WT1 isoforms - three amino acids can make all the difference. Cell $2001 \mathbf{1 0 6} 391-394$.

4 Wagner KD, Wagner N \& Schedl A. The complex life of WT1. Journal of Cell Science $2003 \mathbf{1 1 6} 1653-1658$.

5 Pelletier J, Bruening W, Kashtan CE, Mauer SM, Manivel JC, Striegel JE et al. Germline mutations in the Wilms' tumor suppressor gene are associated with abnormal urogenital development in Denys-Drash syndrome. Cell 199167 437-447.

6 Barbaux S, Niaudet P, Gubler MC, Grunfeld JP, Jaubert F, Kuttenn F, Fekete CN, Souleyreau-Therville N, Thibaud E, Fellous M \& McElreavey K. Donor splice-site mutations in WT1 are responsible for Frasier syndrome. Nature Genetics 199717 467-470.

7 Little M \& Wells C. A clinical overview of WT1 gene mutations. Human Mutation 19979 209-225.

8 Jeanpierre C, Beroud C, Niaudet P \& Junien C. Software and database for the analysis of mutations in the human WT1 gene. Nucleic Acids Research $1998 \mathbf{2 6} 271-274$.

9 Kohler B, Schumacher V, Schulte-Overberg U, Biewald W, Lennert T, l'Allemand D, Royer-Pokora B \& Gruters A. Bilateral Wilms tumor in a boy with severe hypospadias and cryptochidism due to a heterozygous mutation in the WT1 gene. Pediatric Research $199945187-190$. 
10 Kohler B, Schumacher V, l'Allemand D, Royer-Pokora B \& Gruters A. Germline Wilms tumor suppressor gene (WT1) mutation leading to isolated genital malformation without Wilms tumor or nephropathy. Journal of Pediatrics 2001138 421-424.

11 Koziell A, Charmandari E, Hindmarsh PC, Rees L, Scambler P \& Brook CG. Frasier syndrome, part of the Denys-Drash continuum or simply a WT1 gene associated disorder of intersex and nephropathy? Clinical Endocrinology 200052 519-524.

12 Boudon C, Lumbroso S, Lobaccaro JM, Szarras-Czapnik M, Romer TE, Garandeau P, Montoya P \& Sultan C. Molecular study of the 5 alpha-reductase type 2 gene in three European families with 5 alpha-reductase deficiency. Journal of Clinical Endocrinology and Metabolism $1995802149-2153$.

13 Lumbroso S, Lobaccaro JM, Georget V, Leger J, Poujol N, Terouanne B, Evain-Brion D, Czernichow P \& Sultan C. A novel substitution (Leu707Arg) in exon 4 of the androgen receptor gene causes complete androgen resistance. Journal of Clinical Endocrinology and Metabolism 199681 1984-1988.

14 Gessler M, Konig A, Arden K, Grundy P, Orkin S, Sallan S, Peters C, Ruyle S, Mandell J \& Li F. Infrequent mutation of the WT1 gene in 77 Wilms' tumors. Human Mutation 19943 212-222.

15 Schumacher V, Schneider S, Figge A, Wildhardt G, Harms D, Schmidt D, Weirich A, Ludwig R \& Royer-Pokora B. Correlation of germ-line mutations and two-hit inactivation of the WT1 gene with Wilms tumors of stromal-predominant histology. PNAS $1997943972-3977$.

16 Reddy JC, Morris JC, Wang J, English MA, Haber DA, Shi Y \& Licht JD. WT1-mediated transcriptional activation is inhibited by dominant negative mutant proteins. Journal of Biological Chemistry $199527010878-10884$.

17 Knudson AG Jr \& Strong LC. Mutation and cancer: a model for Wilms' tumor of the kidney. Journal of the National Cancer Institute $197248313-324$.

18 Melo KF, Martin RM, Costa EM, Carvalho FM, Jorge AA, Arnhold IJ \& Mendonca BB. An unusual phenotype of Frasier syndrome due to IVS9 $+4 \mathrm{C}>\mathrm{T}$ mutation in the WT1 gene: predominantly male ambiguous genitalia and absence of gonadal dysgenesis. Journal of Clinical Endocrinology and Metabolism $2002 \quad 87$ $2500-2505$.

19 Shimamura R, Fraizer GC, Trapman J, Lau YFC \& Saunders GF. The Wilms' tumor gene WT1 can regulate genes involved in sex determination and differentiation: SRY, Mullerian-inhibiting substance, and the androgen receptor. Clinical Cancer Research $199732571-2580$.

20 Kreidberg JA, Sariola H, Loring JM, Maeda M, Pelletier J, Housman D \& Jaenisch R. WT-1 is required for early kidney development. Cell 1993 74 679-691.

21 Armstrong JF, Pritchard-Jones K, Bickmore WA, Hastie ND \& Bard JB. The expression of the Wilms' tumour gene, WT1, in the developing mammalian embryo. Mechanisms of Development $19934085-97$.

22 Perez-Pomares JM, Macias-Lopez D, Garcia-Garrido L \& MunozChapuli R. Immunohistochemical evidence for a mesothelial contribution to the ventral wall of the avian aorta. Histochemical Journal $199931771-779$.

23 Munoz-Chapuli R, Macias D, Gonzalez-Iriarte M, Carmona R, Atencia G \& Perez-Pomares JM. [The epicardium and epicardialderived cells: multiple functions in cardiac development]. Revista Española de Cardiologica 200255 1070-1082.

24 Hammes A, Guo JK, Lutsch G, Leheste JR, Landrock D, Ziegler U, Gubler MC \& Schedl A. Two splice variants of the Wilms' tumor 1 gene have distinct functions during sex determination and nephron formation. Cell $2001106319-329$.

Received 16 February 2004

Accepted 16 February 2004 